\title{
The Role of Radiologist in Conservative Management of Breast Cancer
}

\section{Tarek Aref*}

Professor, Medical Research Institute, University of Alexandria, Egypt

*Corresponding Author: Tarek Aref, Professor, Medical Research Institute, University of Alexandria, Egypt.
Received: February 26, 2020

Published: March 01, 2020

(C) All rights are reserved by Tarek Aref.
Breast conserving therapy (BCT) refers to breast conserving surgery (BCS), followed by moderate-dose radiation therapy to eradicate any microscopic residual breast disease. BCS can almost be considered the gold standard of early stage invasive breast cancer treatment, allowing to achieve adequate surgical margins with an acceptable cosmetic outcome. Role of radiologists in breast cancer management was limited for many years to suggesting an initial diagnosis and detecting loco-regional recurrence after treatment by mammogram and breast ultrasonography. The development of the Breast Imaging Reporting and Data System (BIRADS) of the American College of Radiology (ACR) helps to change Radiologist's role through many factors: standardized the description and recommended management of breast lesions. BIRADS has increased the radiopathological correlation of radiologists' reports, improving the reports' reliability, and has also established a common language for all of the physicians involved in multidisciplinary breast disease management team, favoring agreement on decisions, and Furthermore, advances in breast magnetic resonance imaging; functional MRI and image-guided interventional procedures have increased our responsibility in the therapeutic decision-making process. The role of Radiologist in BCT:I- Accurate and early diagnosis of breast cancer and staging. II- Interventional role of Radiologist in BCT including imaging-guided biopsy of breast masses, stereotactic biopsy of non-palpable lesions and or microcalcifications guided by mammography or MRI. Post-biopsy-clips insertion, and pre-neoadjuvent chemotherapy localization of malignant lesion by US-guided insertion of hydromark (clips). Preoperative localization of non-palpable breast mass or microcalcifications by US-guided insertion of wire. III Evaluation of response to neoadjuvant therapy using RECIST (Response Evaluation Criteria In Solid Tumours).

\section{Assets from publication with us}

- Prompt Acknowledgement after receiving the article

- Thorough Double blinded peer review

- Rapid Publication

- Issue of Publication Certificate

- High visibility of your Published work

Website: https://www.actascientific.com/

Submit Article: https://www.actascientific.com/submission.php Email us: editor@actascientific.com

Contact us: +919182824667 